\title{
A ESPISTEMOLÓGIA DA FORMAÇÃO DE PROFESSORES DE DANÇA: VISIBILIDADES DAS PRÁTICAS FORMATIVAS
}

\author{
LA EPISTEMOLOGÍA DE LA GRADUACIÓN DE PROFESSORES DE \\ DANZA: VISIBILIDADES DE LA PRÁCTICA FORMATIVA
}

\author{
THE ESPISTEMOLÓGIA OF THE TRAINING OF TEACHERS OF DANCE: \\ VISIBILITIES OF THE PRACTICE FORMATIVE
}

\author{
Ricardo Augusto Gomes PEREIRA ${ }^{1}$ \\ Carlos Jorge PAIXÃO ${ }^{2}$
}

RESUMO: Este texto integra as reflexões teóricas do Grupo de Estudos e Pesquisas sobre Teorias, Epistemologias e Métodos da Educação - EPIsTEM/ICED/PPGED/UFPA que converge investigações que sobre a epistemologia no campo educacional. O objetivo do presente estudo é analisar a configuração da epistemologia da formação do professor de dança em artigos publicados entre 2002 e 2017 através de uma revisão sistemática de literatura, a qual se deu a partir da análise de 20 artigos coletados em periódicos nacionais. $\mathrm{O}$ artigo inicialmente expõe a preocupação com a formação de uma epistemologia em torno da formação do professor de dança, a qual subsidiou a reflexão crítica sobre os objetos, referenciais teóricos e metodologias utilizados nos artigos investigados, os quais mostraram que a referida epistemologia se conforma em temáticas como ensino, currículo, escola e na própria formação do professor, além do corpo, identidades e subjetividades como marcadores do conhecimento que habitam a formação do professor de dança enquanto saber científico; isso foi possível identificar pelo tratamento metodológico dado pelos autores e sua busca de compreensão da dança em diversos contextos, mostrando a preocupação com a consolidação da dança como ciência. Constatou-se que a referida epistemologia está configurada sobre a prática escolar e educacional, como também nos conhecimentos que embasam a formação do professor da área, permitindo refletir sobre o delineamento da epistemologia em torno da referida formação, identificando perspectivas para o trabalho doente na Educação Básica e Superior.

PALAVRAS-CHAVE: Epistemologia. Formação do professor. Dança. Currículo. Práticas.

RESUMEN: Este texto integra las reflexiones teóricas del grupo de estudios y pesquisas sobre teorías epistemológicas y métodos de la educación EPISTEM/ICED/PPGED/UFPA que converge investigaciones sobre la epistemología en el campo educacional. El objetivo del estudio presente es analizar la configuración de la epistemología de la graduación del profesor de danza en artículos publicados entre 2002 y 2017 a través de una revisión

${ }^{1}$ Universidade Federal do Pará (UFPA), Belém - PA - Brasil. Doutorando em Educação PPGED. ORCID: <https://orcid.org/0000-0002-1626-6378>. E-mail: pereiraric19@ gmail.com

2 Universidade Federal do Pará (UFPA), Belém - PA - Brasil. Docente do PPGED. ORCID: <https://orcid.org/0000-0002-4528-9907>. E-mail: carlosjpaixao@hotmail.com 
sistemática de literatura, la cual se dio a partir del análisis de 20 artículos colectados en periódicos nacionales. El artículo expone inicialmente la preocupación con la formación de una epistemología entorno de la graduación del profesor de danza, la cual subsidió la reflexión crítica sobre los objetos, referenciales teóricos y metodologías utilizados en los artículos investigados, los cuales mostraron que la referida epistemología se conforma en temáticas como enseñanza, currículo, escuela y en la propia formación del profesor, más allá del cuerpo, identidades y subjetividades como marcadores del conocimiento que habitan la formación del profesor de danza en cuanto al saber científico y esto fue posible identificar por el tratamiento metodológico dado por los autores y su búsqueda de comprensión de la danza en diversos contextos, mostrando la preocupación con la consolidación de la danza como ciencia, se constató que la referida epistemología está configurada sobre la practica escolar y educacional, como también en los conocimientos que basan la formación del profesor de la área, permitiendo reflexionar sobre el delineamiento de la epistemología entorno de la referida formación, identificando perspectivas para el trabajo docente en la educación básica y superior.

PALABRAS CLAVE: Epistemología. Graduación del profesor. Danza. Currículo. Prácticas.

ABSTRACT: His text integrates the theoretical reflections of the Group of Studies and Research on Theories, Epistemologies and Methods of Education EPISTEM/ICED/PPGED/UFPA that converges investigations that on the epistemology in the educational field. The objective of the present study is to analyze the configuration of the epistemology of dance teacher training in articles published between 2002 and 2017 through a systematic literature review, which was based on the analysis of 20 articles collected in national journals. The article initially exposes the concern with the formation of an epistemology surrounding the training of the dance teacher, which subsidized the critical reflection on the objects, theoretical references and methodologies used in the investigated articles, which showed that the referred epistemology is conformed in thematic such as teaching, curriculum, school and the teacher's own formation, besides the body, identities and subjectivities as markers of knowledge that inhabit the teacher training of dance as scientific knowledge and this was possible to identify by the methodological treatment given by the authors and their search for understanding of dance in various contexts, showing concern for the consolidation of dance as a science. It was verified that this epistemology is configured on the school and educational practice, as well as on the knowledge that supports the formation of the teacher of the area, allowing to reflect on the delineation of the epistemology surrounding said formation, identifying perspectives for sick work in Education Basic and Superior.

KEYWORDS: Epistemology. Tteacher training. Dance. Curriculum. Practices.

\section{Introdução}

A aprovação da Lei de Diretrizes e Bases da Educação Nacional de 1996, através da Lei 9.394, coloca em evidência reformas na educação nacional com destaque para 
modificações na organização curricular, como também alterações na atuação do profissional da educação, em especial no ensino de arte, área que passou a ter tratamento diferenciado do que era previsto na Lei 5.692 de 1971, já que esta passou a ser componente curricular obrigatório nas escolas brasileiras.

Sendo assim, a referida lei representou um avanço na superação da antiga noção de "educação artística", que consistia um saber propedêutico a ser aplicado na escola, e por outro ângulo, anunciava consigo a expressão "ensino das artes", que camuflava a sua real definição, logo, não foi possível distinguir em qual ramo estava relacionada, colocando em risco o prosseguimento da mesma prática, que resultava em um trabalho rápido e pouco reflexivo. Embora as Diretrizes Curriculares Nacionais (DCN's) de 1997 instruírem conteúdos voltados para as linguagens artísticas do teatro, dança, música e artes visuais, o que suscitou a reabertura da discussão sobre o caráter polivalente no ensino de arte, pois não havia sua real execução.

Diante do exposto, a imprecisão no desenvolvimento do currículo escolar motivou a mobilização de educadores, artistas e intelectuais das artes, em prol da ressignificação do campo de atuação do ensino de artes, que se destinava a aplicar maior benefício para a educação. Dessa maneira, a culminância da Lei 11.769/2008 promoveu a alteração da LDBEN, com a finalidade da implantação da música como conteúdo obrigatório no ensino de artes. Desde então, observa-se que as demais linguagens artísticas passaram a ocupar seus espaços no ensino nacional de acordo com o dispositivo da Lei 13.278/ 2016, em concordância ao artigo 26 da LDBEN na inclusão da dança, teatro, música e artes visuais como componente curricular nos diversos níveis e modalidades da Educação Básica.

É oportuno lembrar que são 22 anos de discussões, nos quais embates e conquistas alcançados são ameaçadas pelas determinações do atual governo brasileiro que tem levado a cabo uma série de reformas, entre elas a do Ensino Médio, que tornou optativo o ensino de Artes, Educação Física, Sociologia e Filosofia, acarretando perdas sem tamanho que formam via escola mais autômatos do que cidadãos; Barbosa $(2017$, p. 9) reitera profunda preocupação ao afirmar:

O conhecimento crítico de como os conceitos visuais, sociais e históricos aparecem na arte, como eles têm sido percebidos, redefinidos, redesignados, distorcidos, descartados, reapropriados, reformulados, justificados e criticados em seus processos construtivos, ilumina a prática da arte, mesmo quando essa prática é meramente comercial. 
A preocupação da autora com o contexto atual do ensino de artes mostra o desapego político com a área, junto a força dos atores sociais, considerando não somente os artistas, mas também educadores e intelectuais envolvidos na cena social, política e educacional, já que os referidos atores emergem do que Silva (2005, p. 38) chama de "dramas sociais", que, segundo essa autora,

[...] emergem nos "interstícios da estrutura social", propiciando aos atores sociais a experiência concreta de estarem às margens da sociedade e criando ocasião para pessoas ou grupos representarem, simbolicamente, papéis que correspondem a uma posição invertida em relação ao status ou condição que ordinariamente possuem no quadro hierárquico da "estrutura social".

Mesmo com a percepção do autor definindo o conceito de atores sociais sob o prisma antropológico, essa reflexão colabora com a compreensão de que o ensino de artes com qualidade para todos os brasileiros prescinde de comprometimento político e profissional com o campo da arte. Neste seguimento, em meio a todos esses acontecimentos, observa-se que também houve um amplo movimento pela qualificação de professores que atendessem ao ensino de arte por suas linguagens.

No artigo "Profissão professor de dança: Uma breve cartografia do ensino de dança no Estado de São Paulo", Strazzacappa (2011) analisa a formação de professores por linguagens artísticas, em particular a formação do professor de dança. Nesse estudo, a autora discute o caráter extracurricular que ainda impera no ensino de arte e aponta a necessidade de formação de professores em áreas específicas da arte, como dança, Teatro, Música e Artes Visuais. Ademais, esse é somente um exemplo que envolve a problemática em torno da formação do professor de dança, já que nos últimos 15 anos observa-se a formação de um campo epistemológico em torno da formação do professor de dança que tem guiado a referida linguagem na área de artes.

Em uma tentativa de aproximar os pressupostos teóricos que dão suporte à produção do conhecimento válido sobre problemas relativos à formação de professores na área de dança, tem correspondência epistemológica, conforme observa-se abaixo:

O conceito de epistemologia é, pois, empregado de modo bastante flexível. Segundo os autores, com seus pressupostos filosóficos ou ideológicos, e em conformidade com os países e os costumes, ele serve para designar, quer uma teoria geral do conhecimento (de natureza mais ou menos filosófica), quer estudos mais restritos interrogando-se sobre a gênese e a estrutura das ciências, tentando descobrir as leis de crescimento dos conhecimentos, quer uma análise lógica da linguagem 
científica, quer, enfim, o exame das condições reais de produção dos conhecimentos científicos (JAPIASSU, 1992, p. 38).

Assim, nossa incursão analisando a pesquisa e produção do conhecimento na formação do professor de dança vem demonstrando a composição gradual de um corpus teórico que pode ser anunciado como uma epistemologia, cuja noção deve superar o paradigma da racionalização e disciplinaridade presente em uma noção tradicional de dança, mas que na atualidade vem sendo combatida.

A problemática em torno da formação do professor de dança, por meio dos autores analisados e, suas produções nos últimos 15 anos, confirmam a formação de um campo epistemológico em torno da dança que tem guiado a referida linguagem na área de ensino. Japiassu (1975, p. 16) aponta que um campo epistemológico se constitui a partir "estudo metódico e reflexivo do saber, de sua organização, de sua formação, de seu desenvolvimento, de seu funcionamento e de seus produtos intelectuais”. O princípio apontado por Japiassu mostra que a epistemologia se constitui uma forma de identificação de discursos em torno de um campo, avaliando sua natureza específica que segundo o referido autor,

[...] se trata de levar em conta uma disciplina intelectualmente constituída em unidade bem definida do saber, e de estudá-la de modo próximo, detalhado e técnico, mostrando sua organização, seu funcionamento e as possíveis relações que ela mantém com as demais disciplinas [...] (JAPIASSU, 1975, p. 17).

Nossa suposição é que o andamento formal e sistemático dos estudos e do conhecimento produzido por meio de processos formais de pesquisa acadêmico-científica sobre a área de dança está constituindo uma epistemologia específica, uma vez que ao sair da informalidade, e se estabelecer como campo científico, considerando que na educação a dança tem sido amplamente prestigiada nas deliberações legislativas que ocorreram no final dos anos de 1990 existentes nos Parâmetros Curriculares Nacionais - PCNs, os quais, sob a orientação da Lei 9.394 de 1996, estabeleceram orientações curriculares para o desenvolvimento das disciplinas, com a finalidade de instruir o aluno a identificar linguagens diversas, sejam elas "verbais, matemáticas, gráficas, plásticas e corporais" e conduzi-los a operar múltiplas habilidades, a fim de atender a "a diferentes intenções e situações de comunicação" (PCN ARTE, 1997, p. 5).

Sob outra perspectiva, os PCNs trouxeram para a educação brasileira debates em relação a outras vertentes educacionais, tais como: o meio ambiente, a sexualidade e 
dignidade humana contemporizadas no currículo escolar na forma de temas importantes à compreensão do mundo atual e seus problemas como exigência do Plano Decenal de Educação Para Todos (1993-2003), visto que atribuía ao estado a tarefa de implantação de uma reforma com aumento de pelo menos 50\% das condições de aprendizagem das disciplinas do núcleo comum.

Sendo assim, não faltaram críticas à configuração que, apesar de consolidada na educação brasileira, balizou os sistemas de avaliação nacional. Nesse caso, os PCNs foram considerados incapazes de reconhecer a heterogeneidade educacional do Brasil, considerando que tal reforma precisava de mudanças para além de uma mera melhoria curricular, como a que ocorreu no final dos anos 90; atualmente, passados 18 anos, mais uma vez é repensada na forma de Movimento pela Base Nacional Comum³ da capitaneada pelo Ministério da Educação.

Além disso, os PCNs, mesmo valorizando no tocante do ensino da Arte, não assegura a funcionalidade específica do profissional de artes, em especial para os anos iniciais do Ensino Fundamental, no que diz respeito a sua atuação nas diversas linguagens, como artes visuais, dança, música e teatro que representam um vasto conteúdo simbólico e representacional que se consagram em leituras para além da formal centrada na palavra, mas em expressões não verbais que se constituem teores da arte na escola. Desse modo, é indispensável que haja uma exigência importante para o desenvolvimento da referida área, uma vez que sua polivalência, aspecto há muito presente na formação dos professores no Brasil, pois essa prática é advinda da noção de que o professor polivalente possui "atributo do trabalhador contemporâneo, adaptado a contextos diversos e possuidor de competências múltiplas que lhe permitem atuar em diferentes postos de trabalho" (CRUZ; NETO, 2012, p. 387). Essa noção parece danosa não só para a área de arte, mas para toda a educação escolar, pois parecer ser uma exigência do capital que trabalhadores exerçam funções diversas em nome da economia do governo e empresas. Especificamente no campo da arte, existem críticas contundentes que estão relacionadas à qualidade do trabalho com arte nas escolas, que legalmente superou o paradigma da "Educação Artística", mas que na prática continua a tratar essa disciplina enquanto intervenção pedagógica e instrumental.

${ }^{3}$ Segundo informações contidas no site <http://basenacionalcomum.org.br>, o movimento visa dar celeridade ao processo de reconstrução da Base Nacional Comum, instituída pela LDBEN 9394/1996 e na Constituição de 1988, buscando, através dessa mobilização a participação da comunidade educacional na revisão do currículo nacional. 
Observa-se que a dança tem encontrado amplo espaço no meio educacional como conteúdo da disciplina arte e como linguagem contemplada no currículo escolar. Mas é necessário indagar: o que é dança? Qual sua relevância a ponto de ser comtemplada no currículo escolar? Sobre o conceito de dança, Caminada (1999) em publicação on line argumenta que dança está relacionada a movimentos relativos à matéria prima corporal, uma vez que a "[...] capacidade de a dança, justamente por seu processo intrínseco e dinâmico de evolução, manter-se permanentemente atual, ajustando-se às novas concepções de estética através dos tempos, revelando, por isso mesmo, épocas, estados de espírito, sensações [...]".

Daí sua relevância, a dança está relacionada à vida, aos processos criativos humanos que não são criados apenas à descontração, mas estão presentes em todos os momentos da vida, que Caminada (1999) atribui à estrutura intelectual humana a capacidade de performar os atos da vida e isso é altamente educativo, considerando que a dança se constitui uma entre as muitas formas de leitura. Observa-se que essa condição foi fundamental para que a dança fosse incorporada como orientação curricular no âmbito dos PCNs, já que compreendem que ela é atividade que pode desenvolver na criança a aptidão ao aprimoramento do movimento corporal, funcionamento e expressividade. Em vista disso, os parâmetros educacionais mostram que: "a dança é também um a fonte de comunicação e de criação informada nas culturas. Com atividade lúdica a dança permite a experimentação e a criação, no exercício da espontaneidade" (PCN ARTE, 1997, p. 49).

Essas premissas, quando vistas à luz da realidade das escolas, observa-se um descompasso, já que a escola ainda prima pela afinidade lógico-racional do que a evidência à poética e reprodução da realidade no ensino da arte e isso se agrava quando se trata de dança, pois a ausência de professores com formação específica para atuar em Arte/Dança, notando que essa ideia, apesar de amplamente legislada, ainda não tem ressonância em concursos públicos que continuam a publicar editais generalistas para efetivação de professores de arte.

Ressalta-se que antes das problemáticas que envolvem a dança no âmbito da escola, é notório o surgimento de uma construção de cunho epistemológico em torno desse saber, especialmente nos últimos 15 anos, já que nesse período observa-se a crescente produção de conhecimento acadêmico da dança que tem se caracterizado pela sua utilidade à formação de professores do referido campo e dela mesma enquanto linguagem artística, que segundo Tesser (1995, p. 92), explana uma epistemologia que “[...] propõe soluções 
claras para tais problemas, soluções consistentes em teorias rigorosas e inteligíveis, adequados à realidade da investigação científica [...] é capaz de criticar programas e mesmo resultados errôneos, como conseguir novos enfoques promissores", entre outros aspectos que confirmam a produção do conhecimento em dança, mas que precisam ser questionados: Como essa epistemologia vem se delineado na produção do conhecimento? Quais autores e obras são mais utilizadas para especificar o referido campo epistemológico? Qual o tratamento metodológico está guiado à produção do conhecimento na formação do professor de dança?

Para responder esses questionamentos, optou-se pela realização de uma revisão sistemática de literatura, procedimento que cunho secundário, já que se utiliza de estudos primários para constituir suas análises, sendo que esse tipo de revisão tem sido mais utilizado na área de saúde em estudos clínicos, que segundo Galvão e Pereira (2014, p. 183):

No entanto, há número crescente de revisões preparadas com base em investigações observacionais, como as de coorte, de caso-controle, transversal, série e relato de casos. Outros delineamentos utilizados são os estudos de avaliação econômica e os qualitativos. Quando se verifica que os estudos primários incluídos em revisão sistemática seguem procedimentos homogêneos, os seus resultados são combinados, utilizando-se técnicas de metanálise.

O delineamento de revisões sistemáticas, como pode ser observado na arguição dos autores, pode acontecer de diversas maneiras e ampliam o caráter qualitativo da investigação, o que representa um avanço, especialmente na área de ciências humanas, a qual ainda se detém em análise de caráter "narrativo-literário" sem assumir procedimentos especificos para esse fim, que segundo Filho et al (2014, p. 207),

A falta de critérios sistemáticos gera vários efeitos perversos. Por exemplo, o que garante que uma amostra representativa dos estudos sobre determinado fenômeno foi devidamente selecionada? Na ausência de procedimentos específicos de coleta de dados: nada. [...] um problema típico dos modelos tradicionais de revisão da literatura é a inclusão seletiva de estudos, em geral baseada nas impressões do revisor sobre a qualidade dos trabalhos. Isso porque as revisões tradicionais geralmente utilizam um critério a posteriori para julgar se um determinado estudo deve ou não ser incluído.

No presente estudo, o processo seletivo dos dados que foram coletados a partir da escolha de artigos que obedeciam a dois critérios básicos a serem publicados em periódicos qualificados pela Comissão de Aperfeiçoamento de Pessoal em Nível Superior (CAPES). 
Outrossim, manter relação dos artigos sobre a dança em suas várias formas de expressão e utilização. Assim, foram coletados 20 artigos no período entre 2002 e 2017, período que soma 15 anos que foram analisados dentro das orientações de Galvão; Pereira (2014, p. 183): “(1) elaboração da pergunta de pesquisa; (2) busca na literatura; (3) seleção dos artigos; (4) extração dos dados; (5) avaliação da qualidade metodológica; (6) síntese dos dados (metanálise); (7) avaliação da qualidade das evidências [...]".

O objetivo do presente estudo é analisar a configuração da epistemologia da formação do professor de dança em artigos publicados entre 2002 e 2017, a partir do qual buscamos refletir sobre o delineamento da epistemologia em torno da referida formação, identificando perspectivas para o trabalho doente na educação básica.

\section{Uma leitura no tempo da dança: caminhos teóricos e metodológicos como fonte de conhecimento para formação de professores}

As mudanças que envolvem a dança na atualidade lhe dão novos ares e possibilidades, especialmente à prática no âmbito do ensino e da aprendizagem dessa linguagem da arte, a qual demorou a ser reconhecida como tal, particularmente, antes do advento dos Parâmetros Curriculares Nacionais na década de 1990. A perspectiva histórica da dança aponta que essa prática no âmbito da escola sempre esteve atrelada a situação instrumental. Strazzacappa (2002/2003) reafirma essa posição afirmando que a dança sempre esteve em situação inferior diante das demais práticas artísticas existentes na escola. A autora assevera que na década de 1970,

[...] sua fiscalização é feita por profissionais formados em sua maioria na área de teatro e/ou educação. Na educação básica, isto é, nas escolas de ensino regular, ela costuma ser vista como conteúdo da Educação Física, fato claramente indicado nos Parâmetros Curriculares Nacionais (PCNs) da área dessa disciplina (STRAZZACAPPA, 2002/2003, p. 74).

As críticas dessa autora são importantes porque analisam a situação do ensino da dança na escola, a qual, mesmo com a publicação dos PCNs na década de 1990, pouco mudou, pois a autora identifica que nesse documento que não há uma definição de quais conteúdos a dança deve se dedicar, constatando,

A dança amplia as noções espaciais da criança e do adolescente, situando-os no tempo e no espaço e desenvolvendo sua expressão corporal, mas o teatro também. A dança preocupa-se com a educação estética, mas as artes plásticas também. A dança proporciona o 
desenvolvimento da criatividade e da sensibilidade, mas isso todas as linguagens artísticas proporcionam...Afinal, o que é exclusivo da dança? (STRAZZACAPPA, 2002/2003, p. 74-75).

A perspectiva de Strazzacappa é importante para o presente estudo por se preocupar com a generalidade com qual a dança é tratada nos PCNs de arte. É necessário destacar que a aproximação entre dança e educação: antes desse período, a referida arte era um privilégio de poucos que tinham condições financeiras, como também qualidades físicas das bailarinas, considerando que a mais popular das danças era o Ballet, apontada como exclusivamente de mulheres, mundo proibido para os homens.

O universo das danças clássicas mostrava todo o tradicionalismo que rondava a área que se desenvolvia em escolas de dança, que primavam, como nas escolas formais, pelo virtuosismo, aprimoramento técnico e o espetáculo. Não se dançava para conhecer a si mesmo ou para desenvolver a sensibilidade e o senso estético, ao contrário, a dança tinha como objetivo a exposição, a apresentação, a contemplação.

Sob outra ótica, o movimento artístico da dança foi marcado pelo momento tradicionalista, a qual passou a ser compreendida culturalmente como "escolas", vistas como espaços de aprendizagem para o ensino de "métodos" antes vistos como modernos, que se perpetuavam pelo imperativo desejo de imortalidade que a dança tinha de eternizarse, como foi o caso de Laban com seu estudo do movimento ou como a "Royal Academy of Dancing, hoje entendido como sistema de avaliação" (MARQUES, 2011, p. 51-52).

Além das críticas ao ensino tradicional de dança, é nesse contexto que é criado no Brasil, a partir dos anos de 1950, o primeiro curso superior de dança em 1956, na Universidade Federal da Bahia, o qual foi reconhecido como Licenciatura e bacharelado em 1962. Para Marques (2011, p. 54), a principal crítica que se pode fazer ao ensino universitário de dança no referido momento era que esse ensino, igual à escola formal, era autoritário, funcionalista e sem sentido prático para a vida dos egressos que, ao finalizar o curso, viam-se sem mercado para atuar, a não ser nas escolas de ballet clássico ou corpos de baile dos teatros, que por sinal eram e são poucos no país, as quais deveriam ser substituídas por outra lógica que valorasse “[...] a prática reflexiva que deveria ser trabalhada por essas disciplinas, a fim de pesquisar continuamente e desenvolver práticas pedagógicas significativas e problematizadoras [...]".

Por vinte cinco anos a UFBA foi à única instituição de ensino superior a manter um curso de dança. A partir das décadas de 1980 e 1990, contudo, outras universidades se desafiaram a criar cursos de dança, como o Centro Universitário da Cidade (UNICIDADE) 
no Rio de Janeiro em 1985; a Universidade Estadual de Campinas (UNICAMP) no interior de São Paulo, criado em 1985, mas reconhecido em 1992, ampliando de forma significativa o "o cenário da Dança produzida no Brasil, não só na produção acadêmica como também na produção artística" (MOLINA, 2007, p. 4).

A partir desses períodos, a expansão dos cursos superiores de dança na forma de licenciaturas e bacharelados ganha incrementos regulatórios advindos da aprovação da LDBEN 9.394 de 20 de Dezembro de 1996 e do Decreto 2.208 de 17 de Abril de 1997, os quais deram nova organização para formação profissional em níveis básicos, técnicos e tecnológicos, que, segundo Molina (2007), no caso particular dos cursos tecnológicos, a finalidade era proporcionar formação que tivesse relação com campos específicos do mercado de trabalho, como coreografia, cenógrafo de dança, bailarino, entre outros cursos.

Foi nesse contexto, depois de um largo período de informalidade, que a Escola de Teatro e Dança da Universidade Federal do Pará (ETDUFPA) reconheceu seus cursos de teatro e dança em diversos níveis no ano de 2007. No entanto, a história registra que a UFPA, desde sua fundação em 1957, fomentava o apoio às atividades artísticas nas linguagens de teatro e dança. Nesse sentido, no ano de 1968 a instituição constitui a coordenação de dança da Universidade no âmbito do Centro de Atividades Musicais CAM. Segundo o Projeto Pedagógico da Licenciatura em Dança, desenvolveu sua atuação sob parâmetros pedagógicos baseados em atividades teórico-práticas, marcados pela informalidade do ensino da dança na forma de oficinas de ballet clássico, dança moderna, entre outras modalidades de dança, até que em 2000 o referido trabalho passou a ser ofertado em um curso experimental de formação de bailarinos que em 2003 viria a se transformar no curso técnico em nível médio de dança, que serviu de base para a criação da Licenciatura em dança, o qual obteve reconhecimento em 2007 pela Resolução n. 3.602 de 10 de setembro de 2007 (PPC/ LICENCIATURA EM DANÇA, 2011).

Esse histórico do desenvolvimento da dança no Estado do Pará no interior da UFPA mostra que em todo o Brasil a tendência era a mesma, consolidar uma epistemologia que sustentasse a dança como área produtora de conhecimento científico, inversamente ao contrário do que acontecia, ensino autoritário e bancário e sem sentido para o ensino, pois, segundo Marques (2011, p. 54), o problema das licenciaturas em dança "se veem muitas vezes impotentes frente aos anos de incorporação (trabalho prático corporal) de outros sistemas de representação do corpo, da arte, do sujeito". 
Aliada a essa preocupação, a reforma curricular anunciada pela LDBEN pelos PCNs que inclui a dança como uma das linguagens da Arte e sua obrigatoriedade no currículo da Educação Básica brasileira, foi necessário compreender que a Arte enquanto conteúdo deve proporcionar o maior número de formas ao aluno, "seja no exercício do seu próprio processo criador, por meio das formas artísticas, seja no contato com obras de arte e com outras formas presentes nas culturas ou na natureza" (PCN ARTE, 1997, p. 41).

Apesar do discurso avançado sobre a operacionalização dos conteúdos em Arte, ainda existem questões não resolvidas sobre a formação do professor para atuar em arte no Brasil, cujo percurso formativo, em grande medida, ainda é baseado na polivalência e, sobretudo, na formação do professor para atuar nos anos iniciais do Ensino Fundamental, o qual em tempos atuais, ainda é objeto de mobilização do meio artístico que veem o ensino dessa disciplina na escola como instrumental e intervencionista.

Sobre a dança, especificamente no contexto do ensino da Arte, Marques (2012, p. 17) vê com bons olhos o movimento que se desenvolveu em torno da área, apontando o crescimento dos educadores e legisladores "em pelo menos mencionar a dança em seus trabalhos e programas". Essa observação da autora, em parte, é alusiva à inclusão da dança como linguagem da arte nos Parâmetros Curriculares Nacionais, cujo objetivo é a "compreensão da estrutura e do funcionamento corporal e a investigação do movimento humano" (PCN ARTE, 1997, p. 49).

Há que se criticar nesse objetivo que o mesmo se aproxima da dança como forma de desempenho motor em detrimento do desenvolvimento do senso estético, expressividade e plasticidade que os movimentos devem exibir, os quais ficam em segundo plano, prevalecendo o aspecto motor, precipuamente nos anos iniciais do Ensino Fundamental, período em que as crianças deveriam ser submetidas às mais diversas experiências estéticas corporais, sensoriais e plásticas, permitindo-lhes melhorar seu gosto estético.

Assim, observa-se que a dança, como as demais linguagens da Arte, são campos minados para um debate inconcluso sobre o que é a dança na sociedade brasileira; sobre esse debate, Marque (2012, p. 18-19) se posiciona afirmando que o ensino da dança no Brasil é marcado pela "pluralidade" em diferentes modalidades, produções, propostas educacionais, formas de apoio que "se inter-relacionam, se ignoram, se cruzam, entreolham, multifacetando tanto o mundo da dança quanto o mundo da educação dedicado a ela". 
A crítica de Marques em parte revela que a área possui um corpus teórico que procurar defender diferentes olhares sobre a dança, mas que todos combatem o negligenciamento do corpo enquanto objeto de criação artística. Aponta-se como base de referência teórica Isabel Marques (2011/ 2012); Marcia Strazzacappa (2001); e Débora Barreto (2004), expoentes que tem definido o supracitado campo científico da dança no Brasil, com foco na escola regular.

Um ponto nevrálgico, discutido por Márcia Strazzacappa em 2001, expõe que a presença da dança na escola é analisada a partir da crítica ao processo de regulação do ensino da dança no Brasil. Analisando que o fato de ter sido citada nesses documentos não garantiu um lugar de destaque para a dança no currículo escolar. Entre tantos estudos, Strazzacappa postula que a dança ainda se encontra no terceiro mundo das artes por estar em busca de um espaço sólido na educação.

Débora Barreto (2004) parte do princípio educativo de que a Arte na escola pode ser desenvolvida a partir do que ela denominou de "escola palco", a qual acolheria a dança através de "atitudes dançantes", caracterizadas pelo "improvisar, compor, apreciar e fruir". É possível observar na teoria de Barreto que a referida proposta transforma o sentido da escola e do currículo, pois ao fazer dos mesmos o palco para realização das atividades, a autora indica que dança se torna componente curricular interdisciplinar por meio das demais disciplinas do currículo, improvisando, compondo e principalmente apreciando o conhecimento produzido por ela.

Isabel Marques, nas obras intituladas: "Ensino da dança hoje: Textos e contextos" (2011) e "Dançando na escola" (2012), mostra seu protagonismo, marcando o papel da dança na escola regular, como também críticas profundas sobre as formas de como as atividades de dança e educação se relacionavam. Por esse viés, foi proposta a ruptura com referência de dança feita para festinhas e datas comemorativas, passando assim a assumir a forma democrática que lhe é peculiar, pois "o fato do Brasil ser um país 'dançante' tem também alijado a dança da escola" (MARQUES, 2012, p. 21).

Em suma, é válido frisar que as três autoras mencionadas são bailarinas, fazendo com que tal circunstância potencialize a militância de cada uma em prol da popularização da dança na escola, visto que é inegável a contribuição delas para a consolidação do corpus teórico do estudo em curso. Nesse sentido, considera-se a produção acadêmica elaborada por elas fornece subsídios epistemológicos e metodológicos ao ensino, como também 
crescentes análises sobre a dança na escola, que nos faz retomar a relação retilínea com a formação do profissional de arte pela dança.

Em vista do que foi investigado, observa-se na revisão sistemática de literatura que a proposta para o delineamento da dança como campo epistemológico na formação de professores vem se destacando, em razão da necessidade de superação do papel reprodutor da dança, na construção do conhecimento. Tais verdades provêm da busca realizada nos periódicos nacionais nos quais foram publicados artigos, encontrados nos escritos com a temática da dança como objeto de debate central. De forma reflexiva, Trevisan; Schwartz (2011, p. 361) apresentam ao campo os seguintes pontos:

[...] potencial de ação intervindo em diferentes âmbitos do conhecimento, os quais abrangem os domínios artístico, psicológico, emocional, cultural, social, educacional e outros, todos essenciais ao desenvolvimento do indivíduo, e trazem repercussões na qualidade da vida humana.

Diante do exposto, a dança possui um poder de intervenção em fluxo de movimento crescente, visto que na busca pelos artigos foi possível constatar uma gama de objetos, transversalizados pela dança, os quais versam entre as temáticas do corpo, produção do conhecimento acadêmico, dança, escola, ensino e currículo e formação do professor.

Observa-se que a dança enquanto produção do conhecimento é o objeto recorrente nos artigos investigados, assim como na dança, escola, ensino e currículo e formação do professor e os estudos sobre o corpo. Esses foram os objetos mais evidenciados nos artigos examinados. Todavia, foram identificados outros como dança contemporânea, etnografia, dança de idosos e dança e política. A relação entre dança e esses objetos apontam para ampliação de práticas geradoras de reflexão individual e coletiva.

[...] a linguagem da dança sempre esteve atrelada a uma experiência coletiva de criação, muito mais pautada na complexa rede de significações e subjetividades que cada integrante trazia ao todo, do que em uma relação de aprendizado ou assimilação de conteúdos técnicos que pudessem depois ser utilizados na criação (MARTINS; GATTI, 2016, p. 2).

Esses cinco grupos de objetos que transversalizam a produção de conhecimento em dança, confirmam que tais temáticas vão além dos campos comumente estudados. Dessa maneira, são considerados temas que clamam pela subjetividade, a identidade das pessoas, reverberando que a dança hoje é um campo aberto a superar suas raízes tradicionais. Outro destaque importante está relacionado ao período em que as produções foram publicadas, 
uma vez que houve de forma intensa a divulgação desses trabalhos, entre os anos de 2011 e 2015, coincidentemente período que antecedeu a Lei 13.278 de 2016, apesar de existirem artigos desde 2002 e se estendem até 2017 que tratavam do objeto da dança em diferentes contextos, o que mostra a preocupação dos autores com o desenvolvimento tanto teórico como com as práticas de dança na escola.

Sob esta ótica, Araújo; Rebolo (2012), ao analisarem o currículo de licenciatura em dança da universidade Estadual do Mato Grosso do Sul, apontam a intensificação dos debates e ações em torno do ensino da arte, que colaboraram fortemente para a implantação de cursos de graduação em dança no Brasil entre 1980 e 2015. Em contrapartida, especialmente a partir de 2000, corrobora que o movimento não se constitui apenas em uma epistemologia vazia, mas na construção de um corpo teórico-prático que tem tido ressonância nas universidades, em razão de atender à necessidade de formar professores especificamente na área de artes, especialmente a dança, e com relação à temática os autores alertam que,

Os cursos de licenciatura, nesse contexto, se propõem a atender à legislação brasileira que considera o licenciado como o único habilitado a atuar na educação básica formal. No entanto é importante lembrar que, na história dos cursos de Graduação de Dança, o professor formado acabava encontrando como campo de trabalho a modalidade de educação nãoformal (ARAÚJO; REBOLO, 2012, p. 180).

Mesmo com a preocupação dos estudiosos com a informalidade que ainda assombra o professor de dança, é importante notar o caráter articulador que existe entre pesquisadores e professores em um esforço de fortalecer a atividade de dança enquanto linguagem da arte necessita de pessoas formadas para atuar nas escolas, afastando a polivalência que ainda persiste sobre esse ensino.

Antes de adentrar no universo teórico da pesquisa, é necessário destacar que uma epistemologia se consagra pelo seu caráter de saber, como algo presente no cotidiano que aos poucos vai adquirindo uma sistematização em processo pedagógico próprio de repasse. Diante desse entendimento, Japiassu (1975, p. 15) assevera que o saber possui lados bastante distintos, sobre os quais o autor, explica:

Neste sentido bastante lato, o conceito de "saber" poderá ser aplicado à aprendizagem de ordem prática (saber fazer, saber técnico...) e, ao mesmo tempo, às determinações de ordem propriamente intelectual e teórica. É nesse último sentido que tomamos o termo "saber". 
À vista dessa reflexão, entende-se que o campo da dança se encontra submerso, já que esta é uma ação instintiva dos seres humanos independente de geração e etnias, pois desde que nascemos somos condicionados por ela e a atribuímos diferentes sentidos na vida social, na religião, na cultura e em tantos outros momentos, sem necessariamente ser uma atividade somente intelectual, mas que produz saberes para a vida. Destaca-se nesse processo de produção do saber em torno da dança a influência da cultura, sobre a qual Oliveira (2010, p. 105) destaca que,

Ao conhecer e experiênciar sua cultura e as outras o ser humano valoriza a diversidade cultural como também amplia seu conhecimento cultural. Ao acontecer à construção e evolução de nossa história, fica mais fácil compreender a cultura do outro, e talvez quem sabe, valorizando a cultura preservando nossa memória.

A influência da cultura sobre as ações humanas são determinantes na diversidade de saberes, produzidos em um determinado campo. A presente revisão sistemática cumpre essa tarefa ao identificar o corpus teórico da dança, uma vez existem duas grandes tendências que conduzem a produção do conhecimento na formação do professor de dança. Nesse sentido, a proposta aglutina a produção do conhecimento acadêmico/Escola, ensino e currículo/Formação do professor, e a segunda, que agrega objetivos relativos ao Corpo e identidades/subjetividades:

1. Essa tendência é fortemente influenciada pelas determinações legais dos últimos 22 anos, especialmente a partir de 2008 com a instituição da Lei 11.769/2008, que inclui obrigatoriamente o ensino da música incluso no ensino de arte, e posteriormente pela Lei 13.278 de 2016, tal como é realizado com as demais linguagens (dança, teatro e artes visuais). Considerando essa premissa, foi possível desenvolver em forma de diagrama três movimentos distintos, os quais são:

Figura 1: Diagrama - Movimentos distintos

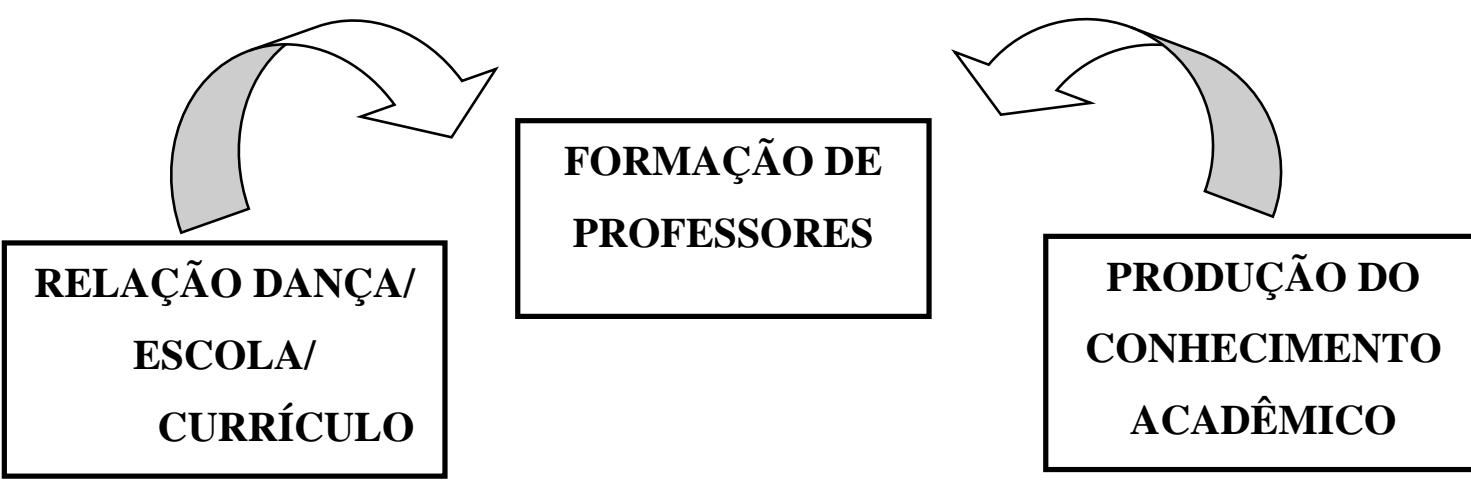

Fonte: autores 
Esse esquema ilustra o movimento que a constituição epistemológica está ampliando no campo da dança ou da formação do professor de arte dança. Sendo assim, considera-se que a partir da revisão realizada o movimento teórico dos autores converge para o fortalecimento da formação de professores com a afirmação da identidade da dança na escola, enquanto componente curricular. Neste seguimento, a reflexão está vinculada à realidade teórica de Isabel Marques, Márcia Strazzacappa, Lívia Brasileiro, Débora Barreto, que por outro lado, os PCNs de arte possuem relevância nesses 15 anos de produção acadêmica.

Dentre esses autores, é incontestável a relevância de Isabel Marques para consolidação da epistemologia em torno da formação de professores de dança, uma vez que a referida autora tem defendido o ensino da dança na escola regular. Contudo, Brasileiro; Filho (2017), apontam que a importância da referência teórica não reside somente em pontuar as mazelas do ensino da dança no Brasil, mas, para além disso, com a finalidade de orientar a prática na escola formal, tornando a dança uma atividade curricular que segundo eles,

\begin{abstract}
Além de apontar problemas visíveis na cena da dança do país, especificamente na escola, Marques expõe contribuições bastante significativas que dão suporte para tratar os possíveis problemas e para que os professores possam conseguir trabalhar este conteúdo na escola, baseado em conteúdos específicos de dança e relacionando-os com questões socioculturais, abrangendo conhecimentos diversos através da interdisciplinaridade (BRASILEIRO; FILHO, 2017, p. 225).
\end{abstract}

Pode-se notar que a produção teórica de Isabel Marques para o campo da dança na escola é decisiva para a conformação de uma teoria em torno da dança, já que a mesma comparece e encontra-se presente em todos os artigos investigados especialmente a partir de 2007, influindo na elaboração de projetos pedagógicos de licenciaturas em dança das universidades brasileiras, ancoradas aos autores consagrados no campo da arte e da teoria do currículo tais como: Ana Mae Barbosa (1991), Antonio Flávio Moreira (1997), Ivor Goodson (1995).

Diante da consistência teórica da autora supracitada observa-se latente que, especialmente entre 2011 e 2016, as publicações dos estudos que analisaram a produção do conhecimento na formação de professores. Logo, foram identificados 05 artigos que tratavam de estados da arte com resultados quantitativos sobre a produção acadêmica na formação do professor de dança, os quais partiram da hipótese presente em todas as 
produções, onde afirmam que na escola está evidenciada como na disciplina de artes e em outras, como Educação Física. Diante dessa afirmativa, destacamos que,

[...] por estar inserida em campos que trazem questionamentos existenciais próprios, que ainda não veem seu lugar e nem são vistos claramente dentro do contexto escolar, campos estes que precisam de uma identidade mais forte e maciça em sua formação, que forme profissionais que saibam agir no seu campo de atuação e não simplesmente dar um jeitinho de passar seus conhecimentos (BRASILEIRO; SOUZA; FRAGOSO, 2015, p. 4).

Essas constatações são confirmadas pelos autores ao apontarem o crescente interesse pelo campo da dança na formação de professores, seja ela em Arte ou em Educação Física, já que tem sido prática educativa por excelência com a capacidade transversal, devido ao seu conteúdo polissêmico em diversas manifestações sociais, sendo eixo de motivação para amplas verificações do que se está produzindo nessa área, que buscam analisar "a produção do conhecimento relativo ao fenômeno dança e suas especificidades" (MUGLIA-RODRIGUES; CORREIA, 2013, p. 92).

É necessário destacar quanto à produção acadêmica na formação do professor de dança que todos os estudos verificados apontam a dança para além do movimento humano, alcançando aspectos estéticos dos saberes produzidos por esta prática, sobre a qual Trevisan; Schwartz (2011, p. 362), analisam que "por meio da experiência de dançar, o sujeito pode compreender melhor a si próprio, as pessoas e o ambiente ao seu redor, bem como perceber e buscar formas mais sensíveis e humanizadoras de aplicar esse conhecer". Embora uma gama de estudos publicados aborda a dança como uma subárea da Educação Física, Oliveira (2010) vê essa situação como "mal-estar", considerando que, a partir das determinações legais, ocorreu o acirramento entre as referidas áreas em prol do domínio do conhecimento produzido.

Toda essa argumentação converge para a centralidade da formação de professores e sua profissionalização, qual foi decisiva para fazer com que a dança ultrapassasse o limite da informalidade, impulsionada pela legislação que exigia a formação do professor em nível superior, segundo determina o artigo 62 da Lei 9.394 de 1996, afastando o "habilidoso", o "talentoso" ou o que "leva jeito" para a dança e assumindo o profissional habilitado para exercer essa função (STRAZZACAPPA, 2011).

Nos estudos analisados, a presente revisão sistemática aclara uma vasta dimensão acerca do esforço para profissionalizar os profissionais da dança, com intuito de capacitá- 
los para atuar nas escolas, uma vez que este espaço é relativamente novo para esses profissionais, que por muito tempo ficaram na condição de informais, que segundo Strazzacappa (2011, p. 28-29),

[...] verificou-se que os professores que atuavam nas escolas livres de dança (conservatórios, academias, estúdios de dança) não tinham necessariamente um curso superior, mesmo porque não the é exigido (seja na própria área de dança, áreas afins ou ainda em outras áreas do conhecimento) e eram, em sua maioria, egressos das próprias escolas. Isso evidenciava que nos cursos de formação artística, as escolas se retroalimentavam, formando artistas da dança que, por sua vez, acabam se tornando os instrutores da própria instituição, perpetuando a genealogia de um estilo ou linha de dança.

As exigências legais de fato estão reverberadas sobre a prática e empoderamento na área de dança enquanto área de conhecimento que se manifestam diretamente na organização curricular das licenciaturas em dança, a qual, no coletivo das formações em arte, consolida a não polivalência, promovendo acesso à formação dos perfis baseado na formação do professor-pesquiador, pois formar não se restringe apenas ao tempo em que o professor passa na academia, mas no conjunto de experiências, que ele amadurece antes do egresso do âmbito acadêmico, fator característico da formação da dança.

Essas constatações comprovam o que Japiassu (1975, p. 10) considera fundamental na identificação de um campo epistemológico, já que "uma reflexão epistemológica, cuja preocupação fundamental é a de situar os problemas como eles se apresentam ou, 'se resolvem ou desaparecem na prática efetiva' dos cientistas". Nota-se que, no caso da formação do professor de dança, sua epistemologia surge a partir dos problemas da prática profissional e artística que podem ser analisados a partir da segunda tendência identificada:

2. A configuração da epistemologia, em relação à formação de professores de dança são os objetos que se relacionam ao corpo, identidade e subjetividade, os quais revelam saberes e como se integram aos diversos campos da dança, em especial a perspectiva artística, que está distante das dimensões profissional e educacional. Se por um lado, a formação de professores de dança tem sido guiada pela tendência de formar professores-pesquisadores, por outro, essa mesma formação tem sido guiada por outra forte tendência que se consagra na expressão bailarino-pesquisadorinterprete, preconizada na teoria de Graziela Rodrigues. 
A referida autora centraliza sua teoria na categoria corpo como parte da história pessoal do bailarino, capaz de tornar visível a identidade e subjetividade. Para Rodrigues (1997, p. 19) essa categoria assume formas que necessitam ser inventariadas, posto que assumem “[...] sensações e configurações decorrentes de imagens de lugares vividos em campo e das imagens 'desconhecidas' situadas em mim mesma. Estas imagens conjugadas apresentavam uma nova configuração de paisagem - espaço onde se desenvolvem experiência de vida, que se instaurava no corpo". A perspectiva de Rodrigues aponta para outro aspecto acerca do corpo, mais identitária do que cartesiana, já que por muito tempo o paradigma de separação entre corpo e mente regulou diversos setores da vida social e cultural que a referida autora com sua teoria, retoma a integração entre ambos pela via etnográfica.

Nos estudos analisados, o corpo se constitui um eixo que integra práticas etnográficas de investigação e experiências que se fundamentam em Fortin (2003), Bourcier (2001) e Bourdieu (2002; 2009), ao discutirem aspectos relativos a identidades culturais e subjetividades de populações ou grupos sociais/ culturais cuja dança é mais que um movimento, mas um enunciado no qual o sujeito representa um participante pronto a comunicar a estética, a ética através do diálogo corporal. Segundo Nascimento (2012, p. 159), as influências do ensino da dança implicam em "[...] diferentes modelos de escolas, com diferentes concepções ideológicas e pedagógicas e levariam em consideração o legado cultural de cada educando".

Esse estudo não estaria completo se não houvesse análise da qualidade metodológica dos estudos investigados, já que todos partiam de uma premissa qualitativa, uma vez que buscavam a interpretação da realidade que envolve a dança em diferentes contextos, e isso foi comprovado pelo comprometimento dos estudos que tinham como objetos a formação dos professores, a escola, o ensino, o currículo, a dança contemporânea, entre outros objetos que denunciam o que Taquete; Minayo (2016, p.429) chamam de compreensão e interpretação de fenômenos, sejam eles com sujeitos ou em contextos teóricos que geram "diferenças de interpretação frequentemente refletem uma compreensão multifacetada de fenômenos sociais complexos". Ressalta-se que mesmo as autoras falem do interior da área de saúde, isso mostra a capacidade interdisciplinar do uso de metodologias qualitativas na verificação que exijam capacidade interpretativa de compreensão. 
Destaca-se que dentre os 20 textos analisados, 15 eram de natureza teórica. Essa tendência metodológica significa o esforço dos autores em estruturar uma teoria que justificasse o caráter científico da formação dos professores de dança. Destaca-se que a referida cientificidade conduz a consolidação do campo epistemológico do objeto investigado, segundo Moser (1987, p. 88), ao analisar os campos teóricos e metodológicos de pesquisas em educação, que,

\begin{abstract}
A idéia orientadora é a própria idéia de cientificidade que pode ser vista como descrição e contemplação (theoria) da realidade, como explicação e previsão do curso dos fenômenos baseados no interesse de intervenção e domínio da natureza: "saber é poder" segundo BACON, ou como transformação da realidade pela práxis. Essas orientações correspondem modelos metodológicos diferentes.
\end{abstract}

Por meio desse viés, observa-se que a teoria para os estudos analisados também buscou o tratamento muito próximo do campo antropológico, com técnicas etnográficas, análise de conteúdo e pesquisa de campo, entre outras que buscavam, além da compreensão do objeto pela via do sujeito, fazer intervenção sobre a realidade desses sujeitos pela dança e seus efeitos.

A verificação da epistemologia da formação de professores de dança permitiu identificar a qualidade dos trabalhos analisados e a preocupação dos autores em reafirmar essa epistemologia que está se configurando entorno do trabalho docente, como algo embrionário, que vem ganhando simetria especialmente a partir de 2008. Ademais, Miranda; Ehrenber (2017) e Rocha; Reser (2015) reafirmam a importância e formação de um campo epistemológico sobre a prática docente do professor de dança dentro Educação Física ou fora dela. Observa-se que a preocupação dos autores foi justamente estabelecer o status à dança de conhecimento científico, que Japiassu (1975, p. 64) afirma que

[...] todo conhecimento científico, embora não funde uma ética ou uma arte objetiva, funda-se numa ética, cujo critério fundamental não é o homem, mas o próprio conhecimento objetivo. E foi esta ética, da felicidade individual e do máximo conforto, que criou a ciência moderna.

Assim, o esforço deste estudo e de todos os que foram analisados foi de examinar a configuração da epistemologia da formação dos professores de dança procurando saber a trajetória que os objetos de investigação trilharam até que dessem à dança a condição de ciência e isso foi possível identificar pelo tratamento metodológico dado pelos autores e sua busca de compreensão e interpretação da dança em diversos contextos, mas não só 
isso, os referenciais teóricos, a escolha dos objetos, as categorias de análise selecionados em todos os artigos mostraram a preocupação com a consolidação da dança como ciência e detentora de uma epistemologia, a qual, como foi possível observar nos 20 artigos examinados, sevem de base para formar professores de dança, e isso é uma intenção crescente.

\section{Considerações finais}

A proposição de analisar a epistemologia da formação do professor de dança em artigos publicados em periódicos nacionais possibilitou constatar que existe uma intensa produção de conhecimento que sustenta a formação desses profissionais, ponderando o relevante papel da legislação na organização curricular do ensino de arte e a formação implementada pelas universidades para atender às determinações legais.

Essas condições impulsionaram a produção do conhecimento acadêmico em torno da formação do professor de dança, cuja ação foi identificada no período entre 2002 e 2017 na publicação de artigos que tratavam de escola, ensino e currículo, formação do professor e a produção acadêmica da área, objetos que mostram a preocupação com a formação do professor de arte na configuração estabelecida em 2013 por força da lei. Esse seria uma das primeiras configurações reconhecida nesse estudo, uma vez que a dança passou a ser conteúdo curricular, disciplina na escola, despertando o interesse profissional que tem gerado o surgimento cursos superiores em dança, que hoje são 33 no Brasil, entre licenciaturas e bacharelados, sendo que as licenciaturas representam a maioria dos cursos de dança das universidades brasileiras, representando 54,5\%, segundo informações do EMEC de 2017.

Essa representatividade das licenciaturas em dança tem provocado reflexões sobre a prática do professor no âmbito das condições das escolas, da operacionalização do currículo e da própria formação do professor. É necessário destacar que persiste um debate no campo da dança, no que diz respeito a quem pertence esse conhecimento, já que a área de educação física reclama esse conhecimento para si, mas a própria dança vem ao longo desse mesmo tempo se desvinculando e se mostrando como uma área autônoma com conhecimento próprio.

Essa autonomia que defendemos neste estudo se apresenta para além do conhecimento da dança no âmbito educacional, ela se configurou na compreensão da dança 
na perspectiva antropológica do corpo, da identidade e da subjetividade humana que tem servido de inspiração, não só para estudos acadêmicos, mas também para produção artística.

Assim, a epistemologia que está presente na formação do professor de dança se deu pela análise crítica da produção do conhecimento na área, que foi facilitada pela revisão sistemática de literatura ao permitir a imersão nos objetos, referenciais teóricos e metodologias utilizadas por pesquisadores para dar visibilidade às investigações publicadas nos artigos coletados, mas acima de tudo, a epistemologia se revelou na reflexão sobre a ciência que está em torno da dança, a qual não está presente no texto dos artigos, mas nas suas entrelinhas.

As perspectivas que se pode apontar na finalização do presente estudo são que ainda é necessário investigar o universo da dança na escola e especificamente a formação do professor, a qual mesmo em crescimento, necessita de mais estudos que consolidem o referido campo enquanto saber, tarefa primordial da epistemologia em qualquer área de conhecimento.

\section{REFERÊNCIAS}

ARAÚJO, Christiane.; REBOLO, Flavinês. A formação do professor de dança: um estudo da licenciatura em Artes Cênicas e Dança da Universidade Estadual do Mato Grosso do Sul. Série-Estudos, n. 39, p. 175-197, jan./jun., 2015.

BARRETO, Débora. Dança: ensino, sentido e possibilidades na escola. Campinas: Autores Associados, 2004.

BRASIL. Lei 9.394 de 20 de dezembro de 1996, Lei de diretrizes e bases da educação nacional. - Brasília: Senado Federal, Coordenação de Edições Técnicas, 2017. p. 58. Disponível em: <http://www2.senado.leg.br/bdsf/bitstream/handle/id/529732/pdf.>. Acesso em: 05 fev. 2018.

BRASIL. LEI N 13.278, DE 2 DE MAIO DE 2016. Altera o $\S 6^{\circ}$ do art. 26 da Lei $n^{\circ}$ 9.394, de 20 de dezembro de 1996, que fixa as diretrizes e bases da educação nacional, referente ao ensino da arte. Disponível em: <www.abmes.org.br>. Acesso em: $05 \mathrm{fev}$. 2018.

BRASIL. LEI No 11.769, DE 18 DE AGOSTO DE 2008. Altera a Lei no 9.394, de 20 de dezembro de 1996, Lei de Diretrizes e Bases da Educação, para dispor sobre a obrigatoriedade do ensino da música na educação básica. Disponível em: <http://www.planalto.gov.br/ccivil_03/_ato2007-2010/2008/lei/111769.htm>. Acesso em: 05 fev. 2018. 
BRASIL. Parâmetros Curriculares Nacionais: Arte. Brasília/DF: Secretaria de Educação Fundamental. Brasília: MEC/SEF, 1997, p. 130.

BRASIL. Plano decenal de educação para todos. Brasília: MEC, 1993 - versão acrescida $136 \mathrm{p}$.

BARBOSA, Ana Mae. O Dilema das Artes no Ensino Médio no Brasil. Disponível em: <https://www.eba.ufmg.br/revistapos/index.php/pos/article/view>. Acesso em: $10 \mathrm{fev}$. 2018.

BRASILEIRO, Lívia Tenório; NASCIMENTO FILHO, Márcio José do. A contribuição de Isabel Marques nas produções sobre "dança" e "ensino de dança" na Educação Física. Rev Bras Educ Fís Esporte, São Paulo, v. 31, n. 1, p. 223-233, jan./mar., 2017.

CAMINADA, Eliana. Reflexões Dança. Sprint Magazine, Cidade, v. 99, n. 104, p. 26-27, set./out., 1999.

CRUZ, Shirleide Pereira da Silva.; NETO, José Batista. A polivalência no contexto da docência nos anos iniciais da escolarização básica: Refletindo sobre experiências de pesquisas. Revista Brasileira de Educação, v. 17, n. 50, p. 385-499, maio/ago., 2012.

FILHO, Dalson Britto Figueiredo et al. O que é, para que serve e como se faz uma metaanálise? Teoria e pesquisa, p. 205-228, 2014.

GALVÃO, Taís Freire.; PEREIRA, Mauricio Gomes. Revisões sistemáticas da literatura: passos para sua elaboração. Epidemiol. Serv. Saúde, Brasília, v. 23, n. 1, p. 183-184, jan./mar., 2014.

JAPIASSU, Hilton. Introdução ao pensamento epistemológico. Rio de Janeiro: F. Alves, 1975, p. 202.

MARTINS, Liana Zakia.; GATTI, Daniela. O processo colaborativo e provisório em dança contemporânea como caminho de construção de saberes. 2016. Disponível em: $<$ http://uece.br/eventos/spcp/anais/trabalhos_completos/247-38824-30032016091634.pdf>. Acesso em: 10 fev. 2018.

MARQUES, Isabel Antunes. Ensino de dança hoje: textos e contextos. São Paulo: Cortez Editora, 6 ${ }^{\mathrm{a}}$ ediç̧ão, 2011. p. 135.

MARQUES, Isabel Antunes. Dançando na escola. 5 ed. São Paulo: Cortez, 2012.

MIRANDA, Rita de Cássia Fernandes.; EHRENBERG, Mônica Caldas. Compondo percursos gestuais: a dança na formação inicial de professores de Educação Física. Curitiba/PR, Brasil. Educar em Revista, v. 33, n. 66, p. 177-192, out./dez., 2017.

MOLINA, Alexandre. A formação de professores de dança no Brasil, 2007. Disponível em: <http://beta.idanca.net/a-formacao-de-professores-de-danca-no-brasil/>. Acesso em: 12 fev. 2018. 
MOSER, Alvino. Tendências epistemológicos-teóricas da pesquisa educacional. Educar, v. 6, n. 1/2, p. 87-99, jan./dez., 1987.

MUGLIA-RODRIGUES, Barbara; CORREIA, Walter Roberto. Produção acadêmica sobre dança nos periódicos nacionais de Educação Física. São Paulo: Rev Bras Educ Fís Esporte, v. 27, n. 1, p. 91-99, jan./mar., 2013.

NASCIMENTO, Eder Fernando do. A problemática do ensino da dança: apropriações preliminares da teoria de Bourdieu. Iniciação Científica CESUMAR, v. 14, n. 2, p. 155-159, jul.dez., 2012.

OLIVEIRA, Eleonôra Nunes. Dança, a quem corresponde na escola: a educação física ou ao ensino de arte?. Grupo de Investigação Educação Arte e Inclusão UDESC. Revista Educação, Artes e Inclusão, Florianópolis, v. 1, ano 3, 2010.

RODRIGUES, Graziela Estela Fonseca. Bailarino-pesquisador-interprete: Processo de formação. Rio de Janeiro: FUNARTE, 1997. 179p.

ROCHA, Deizi Domingues da.; REZER, Ricardo. Estética, formação inicial e dança: Um olhar para a formação de professores de educação física. Movimento, v. 21, n. 4., p. 865-876, out./dez., 2015.

SILVA, Rubens Alves da. Entre "artes" e "ciências": a noção de performance e drama no campo das ciências sociais. Horizontes Antropológicos, ano 11, n. 24, p. 35-65, jul./dez., 2005.

STRAZZACAPPA, Márcia. A educação e a fábrica de corpos: a dança na escola. Cadernos Cedes, ano XXI, n. 53, p. 69-83, abr., 2001.

STRAZZACAPPA, Márcia. Dança na educação discutindo questões básicas e polêmicas. Revista Pensar a Prática, v. 6, p. 73-85, jul./jun., 2002-2003.

STRAZZACAPPA, Márcia. Profissão professor de dança: Uma breve cartografia do ensino de dança no estado de São Paulo. João Pessoa: Rev. Moringa: artes do espetáculo, v. 2, n. 2, p. 27-40, jul./dez., 2011.

TESSER, Gelson João. Principais linhas epistemológicas contemporâneas. Educar. Curitiba/PR: Editora da UFPR, n. 10, p. 91-98, 1995.

TREVISAN, Priscila Raquel Tedesco da Costa.; SCHWARTZ, Gisele Maria. Produção do conhecimento científico sobre dança na perspectiva educacional. Rev. da Educação Física/UEM, Maringá, v. 22, n. 33, p. 361-372, 2011.

TAQUETTE, Stella Regina.; MINAYO, Maria Cecília. Análise de estudos qualitativos conduzidos por médicos publicados em periódicos científicos brasileiros entre $2004 \mathrm{e}$ 2013. Physis Revista de Saúde Coletiva, v. 26, n. 2, p. 417-434, 2016.

UNIVERSIDADE FEDERAL DO PARÁ. Projeto Pedagógico do Curso de Licenciatura em Dança. Belém-Pa: ETDUFPA, 2011. 118p. Disponível em: 
<http://www.aedi.ufpa.br/parfor/arquivos/ppp/PPP_DANCA.pdf >. Acesso em: $17 \mathrm{fev}$. 2018.

\section{Como referenciar este artigo}

PEREIRA, Ricardo Augusto Gomes.; PAIXÃO, Carlos Jorge. A epistemologia da formação de professores de dança: visibilidades das práticas formativas. Revista Ibero Americana de Estudos em Educação, Araraquara, v. 13, n. 03, p. 1066-1091, jul./set., 2018. E-ISSN:1982-5587. DOI: 10.21723/riaee.v13.n3.2018.11135

Submetido em: 28/02/2018

Revisões requeridas: $19 / 04 / 2018$

Aprovado em: 05/05/2018 